\title{
Copper telluride thin films for gas sensing applications
}

\author{
S. H. Salman, N. A. Hassan, G. S. Ahmed* \\ Department of Physics, College of Education for Pure Science (Ibn-Alhaitham), \\ University of Baghdad -Iraq
}

\begin{abstract}
Copper Telluride Thin films of thickness 700nm and 900nm, prepared thin films using thermal evaporation on cleaned Si substrates kept at $300 \mathrm{~K}$ under the vacuum about $\left(4 \times 10^{-5}\right.$ ) mbar. The XRD analysis and (AFM) measurements use to study structure properties. The sensitivity (S) of the fabricated sensors to $\mathrm{NO}_{2}$ and $\mathrm{H}_{2}$ was measured at room temperature. The experimental relationship between $S$ and thickness of the sensitive film was investigated, and higher $\mathrm{S}$ values were recorded for thicker sensors. Results showed that the best sensitivity was attributed to the $\mathrm{Cu} 2 \mathrm{Te}$ film of $900 \mathrm{~nm}$ thickness at the $\mathrm{H}_{2}$ gas.
\end{abstract}

(Received September 27, 2021; Accepted February 17, 2022)

Keywords: Gas sensor, Cu2Te, Thin films, Copper telluride

\section{Introduction}

In the last year, gas sensors have been continuously developing as a result of the increase in industrialization. The basis for the work of sensors the semiconductor resistance change [1]. That results from gas absorption as a result of the interaction of the surface of the semiconductor with the gas applied to it, which is related to the type of semiconductor and its crystal structure [2], where the CuTe is very important in the study of sensing applications. Thin films made of copper telluride have had wide applications in vast fields of science and technology $[3,4]$. Depending on the value of $\mathrm{x}$ the membranes $\left(\mathrm{Cu}_{\mathrm{x}} \mathrm{Te}\right)$ have different crystal structures [5, 6]. CuTe thin films have the direct optical band gap of is around $1.5 \mathrm{eV}$ at room temperature [7].

Prepare CuTe thin films by different methods. such as chemical bath deposition [8], electrodeposition method [9], electron beam evaporation [10], co-evaporation [11], thermal evaporation [12].

K. Neyvasagam et al. [12] Studied the using thermal evaporation, thin films (CuTe) with a thickness of 700 and $900 \mathrm{~nm}$ were prepared on glass substrates.

The present work is the study of the Thin films (CuTe) of thickness from $700 \mathrm{~nm}$ and 900 nm on $\mathrm{Si}(111)$ substrates, and use the thin films as gas sensor applications.

\section{Experimental method}

The CuTe compound prepared from mixture materials copper (99.99\% pure) and $\mathrm{Te}$ (99.99\% pure) into sealed in an evacuated quartz tube under vacuum about $\left(5 \times 10^{-2} \mathrm{mbar}\right)$ and, then the quartz ampoule is heated to $900{ }^{\circ} \mathrm{C}$ for $1 \mathrm{~h}$ in the furnace and then following a quenching by ice water. The ampoule is then broken to get the substance, silicon substrate, then in an ultrasonic cleaner, the parts were cleaned with detergent and ethanol, then washed with deionized water before being etched in a $10 \% \mathrm{HF}$ solution. The CuTe was placed in the molybdenum boat to be vaporized under a vacuum of about $4 \times 10-5$ mbar, kept at room temperature. The thickness of Cupric Telluride thin films was determined by using the weighting method and found to be about $(700 \mp 20) \mathrm{nm}$ and $(900 \bar{\mp} 20) \mathrm{nm}$, with a deposit rate of about $(2.5 \bar{\mp} 0.2) \mathrm{nm} / \mathrm{sec}$. The (XRD) examinations were performed on (SHIMADZU Japan -XRD600) automatic Diffractometer.

\footnotetext{
* Corresponding author: ghzlan82sn@gmail.com https://doi.org/10.15251/CL.2022.192.125
} 
AFM micrographs were taken, type (SPM-AA 3000 contact made spectrometer, Angstrom, USA). To calculate the grain size and morphology of the examined membranes. The gas sensor of CuTe thin films was measured, after putting the sample in the in the chamber which is manufactured locally in a cubic shape. All the measurements of the gas sensor were performed at the temperature of the room.

\section{Result and discussion}

\section{1. $X$ ray diffraction $(X R D)$}

Figure 1 depicted the patterns of the XRD for CuTe thin films, which indicates that the asprepared films have the structure of the polycrystalline and orthorhombic CuTe. However, the intensity of peaks was increased by increasing the thickness of the CuTe thin films.

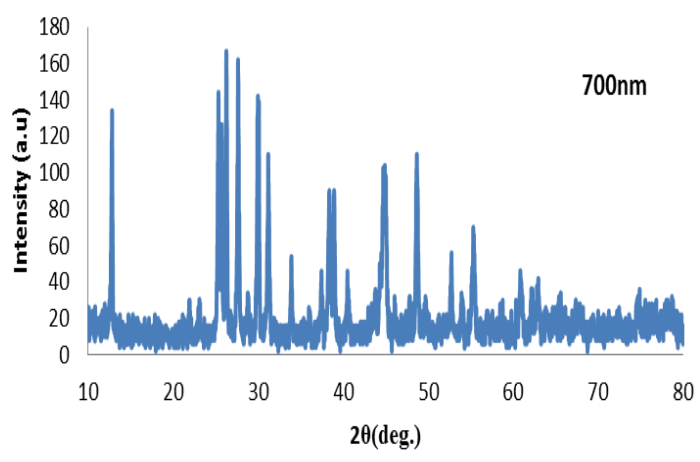

Fig. 1. XRD pattern thin films of thickness 700nm.

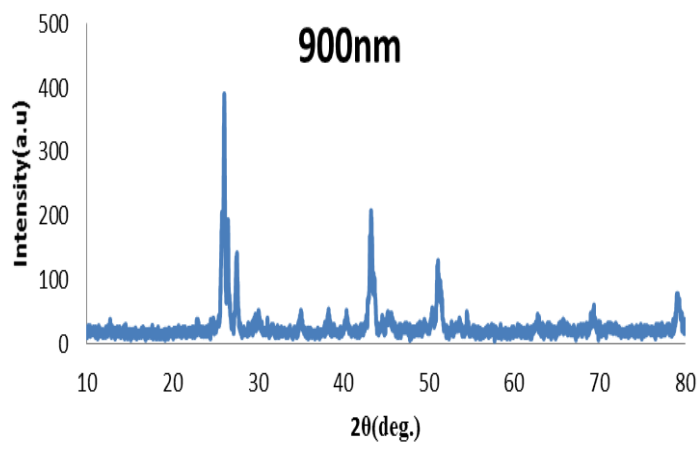

Fig. 2. XRD pattern thin films of thickness $900 \mathrm{~nm}$.

The XRD peaks at $2 \theta=26$ was considered in order to get the parameters of structure, such as the size of the crystalline C.s, average lattice strain $\varepsilon$, the density of dislocation $\delta$ and the crystallites number per area which can be evaluated from the relations below [13-15] and listed in the Table 1.

$$
\begin{gathered}
\varepsilon=\frac{\beta \cos \theta}{4} \\
\text { C.s }=\frac{0.94 \lambda}{\beta \cos \theta} \\
\delta=\frac{1}{(C . s)^{2}}
\end{gathered}
$$




$$
\mathrm{N}=\frac{\mathrm{t}}{(\mathrm{C} . \mathrm{s})^{3}}
$$

where $\lambda$ is $(0.154061 \mathrm{~nm}), \beta$ : is the half maximum at full width in rad, $\theta$ : Angle of Bragg, and t: film thickness.

Table 1. The results of XRD for thin films.

\begin{tabular}{|c|c|c|c|}
\hline \multirow[t]{2}{*}{ Parameters } & \multicolumn{2}{|c|}{ Thickness(nm) } & \multirow{2}{*}{$\begin{array}{c}\text { Standard } \\
\text { Values }\end{array}$} \\
\hline & $700 \mathrm{~nm}$ & $900 \mathrm{~nm}$ & \\
\hline $2 \theta$ & 26.3024 & 26.0918 & 26.6675 \\
\hline $\mathrm{d} \mathrm{nm}$ & 0.33856 & 0.34126 & 0.33400 \\
\hline$\varepsilon$ & 0.000723 & 0.000744 & \\
\hline C.s $\mathrm{nm}$ & 50.038 & 48.67414 & \\
\hline$\delta \quad \mathrm{nm}^{-2}$ & 0.00039 & 0.000422 & ... \\
\hline$N_{o} \mathrm{~nm}^{-2}$ & 0.00718 & 0.007805 & $\cdots$ \\
\hline
\end{tabular}

Table 1 showed the (d and $2 \theta$ ) agreement with standard. The parameters $\varepsilon, \delta$ and $N_{o}$ increases with (t), while the C.s decrease with (t) of the thin film which is found to be (50 and 48) $\mathrm{nm}$ for thickness 700 and $900 \mathrm{~nm}$.

\subsection{Morphology results}

Figure 3 and 4 shows the shows the AFM pictures of CuTe thin film at thickness $700 \mathrm{~nm}$ and thin film of thickness $900 \mathrm{~nm}$, which is the average diameter of thin film, is approximately 126 $\mathrm{nm}$ and surface roughness was estimated around $8.4 \mathrm{~nm}$ for $(700 \mathrm{~nm})$ and is approximately 90.07 $\mathrm{nm}$ and surface roughness was estimated around $5.59 \mathrm{~nm}$ for $(900 \mathrm{~nm})$.

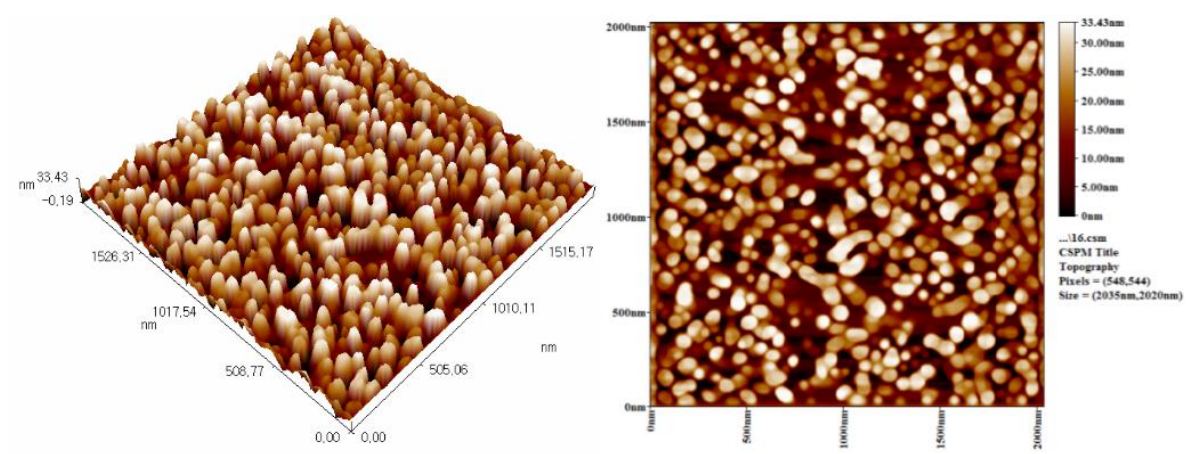

Fig. 3. AFM image of CuTe thin film of thickness 700nm.

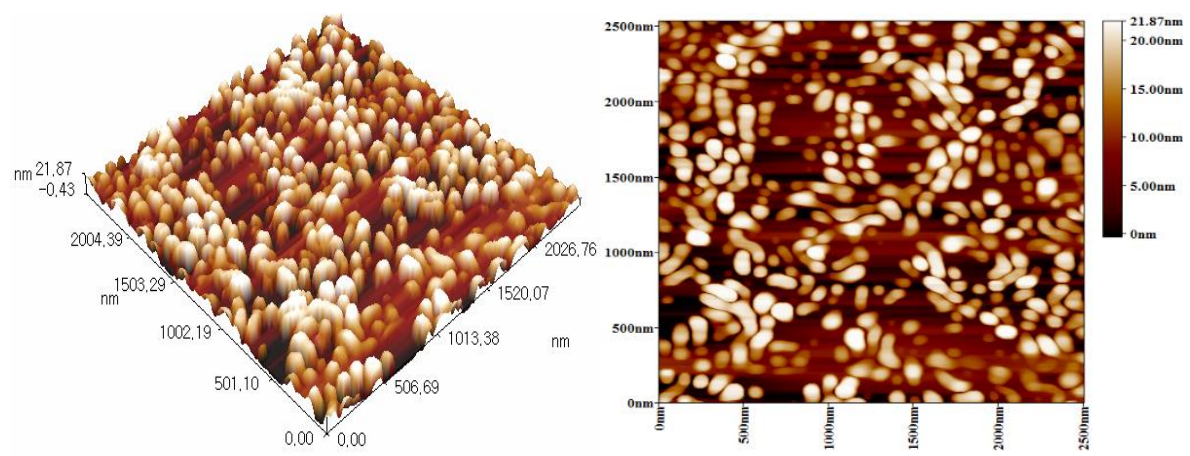

Fig. 4. AFM image of CuTe thin film of thickness $900 \mathrm{~nm}$. 
Table 3. Shows the results of the AFM for the thin films.

\begin{tabular}{|l|l|l|l|}
\hline Thickness & Roughness & RMS & Average diameter(nm) \\
\hline $700 \mathrm{~nm}(16)$ & 8.41 & 9.71 & 126.5 \\
\hline $900 \mathrm{~nm}(1)$ & 5.59 & 6.45 & 90.07 \\
\hline & & & \\
\hline
\end{tabular}

\subsection{The sensitivity results}

The sensors sensitivity can be determined as $[17,18]$.

$$
\mathrm{S}=\left(\frac{R_{g}-R_{a}}{R_{a}}\right) \times 100 \%
$$

where:

$\mathrm{R}_{\mathrm{a}}$ : resistance under air

$\mathrm{R}_{\mathrm{g}}$ : resistance under gas.

The gas sensor spectra of CuTe thin films of thickness $700 \mathrm{~nm}$ and $900 \mathrm{~nm}$ recorded at the room temperature are shown in Figs. (5) and (6).

\subsection{Influence of thickness of thin films on Gas sensitivity}

Figures (5) and (6) exhibited high gas sensitivity for a thin film at thickness (900 nm) for two gases $\left(\mathrm{NO}_{2}\right)$ and $\left(\mathrm{H}_{2}\right)$. These results were interpreted in terms of a decrease in grain size with increased thickness, and increase grain boundaries, as well as an increase in the active surface area due to nanostructure for thin films leading to an increase in sensitivity of thin films.

However, it is clear that the films of this thickness range are unable to provide higher $\mathrm{S}$ values, and other procedures of $\mathrm{S}$ enhancement should be investigated.

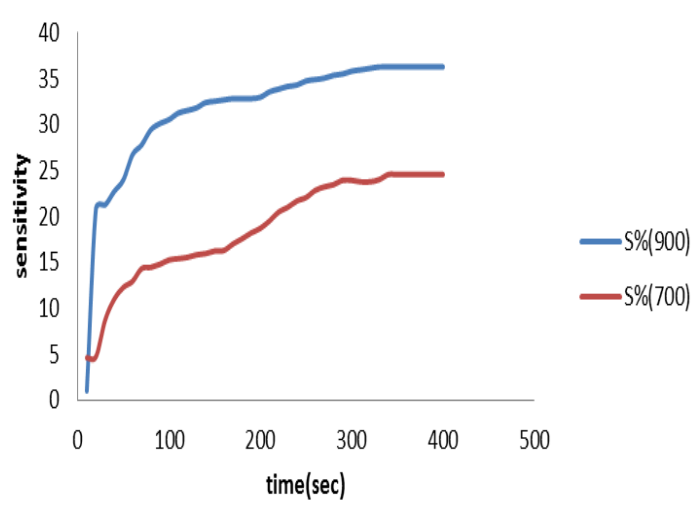

Fig. 5. Shows the gas sensor spectra of CuTe thin films for gas $\left(\mathrm{H}_{2}\right)$.

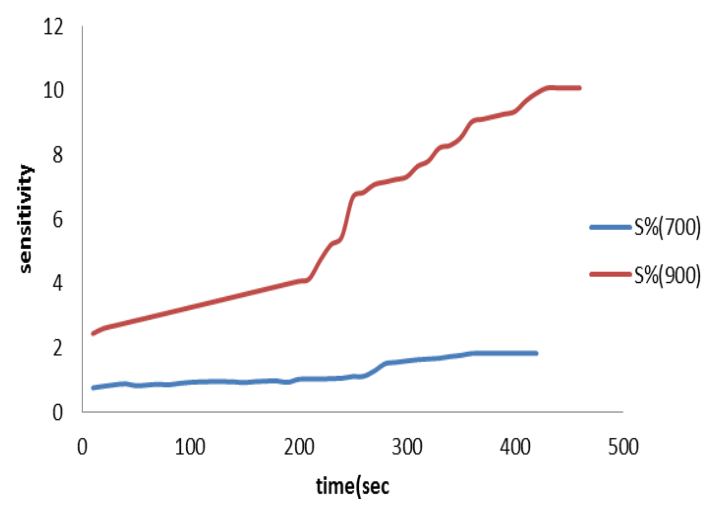

Fig. 6. Shows the gas sensor spectra of CuTe thin films for gas $\left(\mathrm{NO}_{2}\right)$. 


\subsection{Influence of type of Gas on sensitivity}

Figure 7 shows thin film at thickness $(900) \mathrm{nm}$ have higher sensitivity for gas $\left(\mathrm{H}_{2}\right)$ than $\left(\mathrm{NO}_{2}\right)$ due to the nature of the gases, where $\left(\mathrm{NO}_{2}\right)$ An oxidizing gas and $\left(\mathrm{H}_{2}\right)$ a reducing gas.

Results showed that the best sensitivity was attributed to the CuTe film of $(900 \mathrm{~nm})$ thickness at the $\mathrm{H}_{2}$ gas.

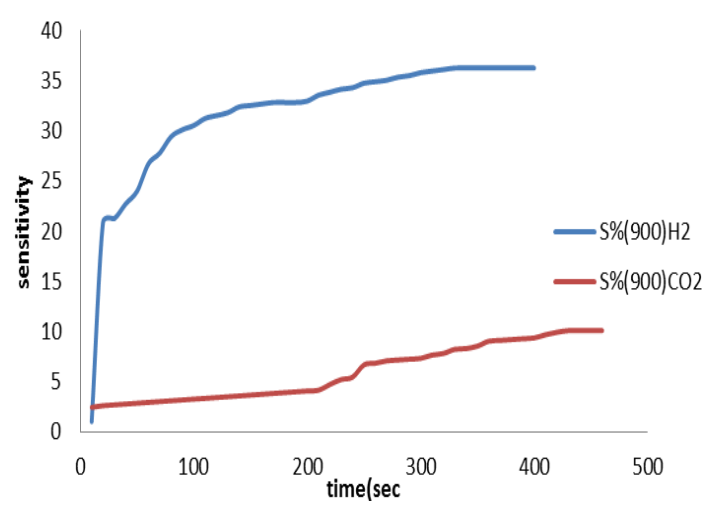

Fig. 7. Shows the sensitivity spectra of CuTe thin films for $\left(\mathrm{NO}_{2}\right)$ and $\left(\mathrm{H}_{2}\right)$ gases.

\section{Conclusion}

The structure of the thin films is of a polycrystalline type and the distribution of the particles is uniform, and this is indicated by the structural (XRD) and the surface (AFM) measurement. The average grain size was estimated around 50nm from XRD measurement. Further, it is observed that there is an increase in the intensity of the peak of CuTe film of thickness $900 \mathrm{~nm}$. high gas sensitivity for a thin film at thickness $(900 \mathrm{~nm})$ for two gases (NO2) and (H2). The best sensitivity was attributed to the CuTe film of $900 \mathrm{~nm}$ thickness at the $\mathrm{H}_{2}$ gas.

\section{References}

[1] W. H. Brattain, J. Bardeen, Bell Syst. Tech. J. 32, 1 (1953); https://doi.org/10.1002/j.15387305.1953.tb01420.x

[2] Artur Rydosz, J. Coatings 8, 425 (2018); https://doi.org/10.3390/coatings8120425

[3] V. J. Fulari, V. P. Malekar, S. A. Gangawane, J. Progress in Electromagnetics Research C 12, 53 (2010); https://doi.org/10.2528/PIERC09103002

[4] K. Neyvasagam, N. Soundararajan, G. Ajaysoni, S. Okram, V. Ganesan, Physica Status Solidi B 245, 77 (2007); https://doi.org/10.1002/pssb.200743111

[5] S. J. Fonash, Solar Cells Device Physics, 78, Academic Press, San Diego, 1981.

[6] H. M. Pathan, C. D. Lokhande, Bull. Mater. Sci. 27, 85 (2004);

https://doi.org/10.1007/BF02708491

[7] K. Neyvasagam, G. Muralidharan, V. Vasu, N. Soundararajan, J. AIP Conf. Proc. 1004, 182 (2008).

[8] Habib M. Pathan, Chandrakant Lokhande, D. P. Amalnerkar, Tanay Seth, J. Applied Surface Science 218(1-4), 291 (2003).

[9] S. S. Dhasade, S. H. Han, V. J. Fulari, J. Semiconductors 33, (2012); https://doi.org/10.1088/1674-4926/33/9/093002

[10] P.V. Bhuvaneswari, K. Ramamurthi, R. Ramesh Babu, J. Thin Solid Films 632, 44 (2017); https://doi.org/10.1016/j.tsf.2017.04.035 
[11] Ya Yang, Taowen Wang, Cai, Liu, Wei, Li, Jingquan Zhang, Lili Wu, Guanggen Zeng, Wenwu Wang, Mingzhe Yu, J. Vacuum, 181 (2017);

https://doi.org/10.1016/j.vacuum.2017.05.014

[12] K. Neyvasagam, N. Soundararajan, Ajaysoni, G. S. Okram, J. I. P. S. S. 245, 77 (2008); https://doi.org/10.1002/pssb.200743111

[13] S. H. Salman, A. A. Shihaba, A. Kh. Elttaye, J. Energy Proceda 157, 199 (2019); https://doi.org/10.1016/j.egypro.2018.11.181

[14] A. A. Shehab, S. H. Salman, J. Ibn Al-Haitham for Pure and Applied Science 25(1), (2012).

[15] S. Hussain, M.Sc. thesis, Inkpoing university, (2008).

[16] G. B. Williamson, R. C. Smallman, philos. Mag. 1, 34 (1956);

https://doi.org/10.1080/14786435608238074

[17] S. S. Çetin, C. M. Baleanu, R. R. Nigmatullin, D. Baleanu, S. Özçelik, Thin Solid Films Journal 519(16), 5712 (2011); https://doi.org/10.1016/j.tsf.2011.04.021

[18] S. H. Salman, A. A. Shihaba, A. Kh. Elttaye, Energy Procedia 157, 283 (2019);

https://doi.org/10.1016/j.egypro.2018.11.192 